\title{
Clinicopathologic characteristics of teenage sporadic colorectal cancer
}

Jae Jun Lee, Sung Hoo Kim, Seok-Byung Lim, Jong Lyul Lee, Chan Wook Kim, Yong Sik Yoon, In Ja Park, Chang Sik Yu, Jin Cheon Kim Division of Colon and Rectal Surgery, Department of Surgery, Asan Medical Center, University of Ulsan College of Medicine, Seoul, Korea

Purpose: Colorectal cancer (CRC) is generally considered a disease of old age. Most CRCs are diagnosed at age 50 and over. CRC rarely occurs in teenagers, and the clinical features and prognosis of CRC are not clear in this population. The aim of this study was to uncover the clinicopathologic characteristics of teenage sporadic CRC.

Methods: Of the 21,042 patients who underwent operation for primary CRC at Asan Medical Center between July 1989 and December 2014, 19 cases (0.09\%) without a familial history of CRC before 20 years of age at diagnosis were enrolled in this study. The clinicopathologic features of the teenage sporadic CRC patients were retrospectively reviewed.

Results: Of the 19 patients, 16 patients (84.2\%) were male. The most common primary site was the left colon (descending colon \& sigmoid colon) in nine patients. With respect to histologic type, adenocarcinoma represented $57.8 \%$ of cases, mucinous adenocarcinoma, 31.5\%, and signet ring cell carcinoma, 10.5\%. Six (31.5\%) patients showed peritoneal seeding at presentation. In survival analysis, the 5-year overall survival rate of the patients who underwent curative surgery was $71.3 \%$.

Conclusion: Teenage sporadic CRC is a very rare disease and the proportion of patients with a poor histologic subtype is high, but early detection and radical treatment can lead to favorable survival rates.

Keywords: Colorectal cancer, Teenage, Sporadic Cancer

\section{INTRODUCTION}

Colorectal cancer (CRC) is the third most common cancer among Koreans and the fourth leading cause of death in Korea [1]. The risk factors of CRC include old age, obesity, race, family history, and smoking. With respect to age, $90 \%$ of all CRC cases were found in patients aged over 50 years [2-5]. In general, it is believed that CRC occurs more frequently in older people. It is, however, possible that sporadic CRC can occur in teenagers, albeit quite rarely, even when they have no family history of CRC. A CRC incidence rate of 0.3-1.5 per million teenagers has been reported [6]. Given the low incidence of CRC, the clinicopathological charac-

Received: Jul 17, 2017 Accepted: Oct 10, 2017

Correspondence to: Seok-Byung Lim

Division of Colon and Rectal Surgery, Department of Surgery, Asan

Medical Center, University of Ulsan College of Medicine, 88 Olympic-ro

43-gil, Songpa-gu, Seoul 05505, Korea

Tel: +82-2-3010-5695, Fax: +82-2-3010-6701

E-mail: sblim@amc.seoul.kr

Copyright @ C Korean Society of Surgical Oncology

This is an Open Access article distributed under the terms of the Creative Commons Attribution Non-Commercial License (http://creativecommons.org/licenses/by-nc/4.0) which permits unrestricted non-commercial use, distribution, and reproduction in any medium, provided the original work is properly cited. teristics of sporadic CRC in young people have not been well documented. The current study therefore aimed to investigate the clinicopathological significance and prognosis of sporadic CRC in young people who underwent CRC surgery before the age of 20.

\section{METHODS}

This retrospective study was conducted to investigate clinicopathological features in young patients under 20 years of age who were selected from 21,042 CRC patients who underwent surgery in the Colorectal Department of Asan Medical Center in Seoul from July 1989 to December 2014. The diagnosis of a CRC lesion was confirmed by a histopathological exam before surgery in the target group. We excluded a case of lymphoma and 4 cases of colonoscopy-detected familial adenomatous polyposis plus a family history. A total of $19(0.09 \%, 19 / 21,042)$ sporadic CRC patients under age 20 met the inclusion criteria. We retrospectively analyzed patient data including sex, primary tumor location, histological subtype, carcinoembryonic antigen levels, surgical technique, and pathological stage using the database of CRC patients and consequent outcomes such as relapse and mortality during follow-up. Prognosis assessment was performed based on survival analysis using the 
Kaplan-Meier method.

The primary tumor location was classified into ascending colon, transverse colon, descending colon, sigmoid colon, and rectum (upper, middle, and lower). CRC is histologically divided into 3 categories: adenocarcinoma, mucinous adenocarcinoma, and signet ring cell type. Both conservative and radical surgical treatments were used, and the patients were classified into TNM stages based on postoperative histopathological results. The follow-up period included a final outpatient visit made after surgery, and the mean follow-up period was 68.9 months.

\section{RESULTS}

There were 16 male patients (84.2\%) and 3 female patients (15.8\%) with an overall mean age of 17.3 years (range, $13-19$ years) at the time of diagnosis. The clinicopathological characteristics of the patients are summarized in Table 1. The lesions were present in the right colon (the ascending and transverse colons) in 3 cases (15.7\%), in the left colon (the descending colon) in 9 cases (47.3\%), and in the rectum in 7 cases (36.8\%). In terms of histological subtype, adenocarcinoma was identified in 11 cases (57.8\%), mucinous adenocarcinoma in 6 cases (31.5\%), and signet ring cell type in 2 cases (10.5\%). Of 19 patients, 10 (52.5\%) progressed to stages III-IV at the time of surgery (4 cases of stage III and 6 cases of stage IV), and peritoneal metastasis was detected during surgery in the stage IV group. Fourteen patients (73.7\%), including 1 patient with partial peritoneal metastasis, were suitable for radical surgery. The clinicopathological characteristics of 19 individual patients are presented in Table 2.

Although the patients for whom only conservative means were allowed had a 1-year survival rate of $20 \%$, the patients who underwent radical surgery showed a 5-year survival rate of $71.3 \%$ (Fig. 1).

\section{DISCUSSION}

A higher incidence of CRC was observed in male teenagers (16/19, $84.2 \%$ ) in this study. Although only 3 cases of CRC were found in female teenagers, they had a severe outcome with an average survival period of 12 months: two of them developed peritoneal metastasis and one had a tumor that spread to the renal fascia as a stage IIIc cancer. Continued studies with larger sample sizes are needed to verify why the incidence of CRC is higher in male teens than female teens and why the latter group had aggressive outcomes.

Researchers are divided in their views regarding the most common site of the first lesion in sporadic CRC among young patients: Some of them reported that CRC was most often located in the as-
Table 1. Clinicopathologic characteristics of the teenage patients with sporadic colorectal cancer

\begin{tabular}{|c|c|}
\hline Variables & Values \\
\hline Mean age (yr) & $17.3(13-19)$ \\
\hline \multicolumn{2}{|l|}{ Sex } \\
\hline Male & $16(84.2)$ \\
\hline Female & $3(15.8)$ \\
\hline Mean body mass index $\left(\mathrm{kg} / \mathrm{m}^{2}\right)$ & $20.3(18.5-22.1)$ \\
\hline \multicolumn{2}{|l|}{ Carcinoembryonic antigen } \\
\hline Normal & 15 (78.9) \\
\hline Elevated & $3(15.8)$ \\
\hline Unknown & $1(5.3)$ \\
\hline \multicolumn{2}{|l|}{ Tumor size } \\
\hline$<5 \mathrm{~cm}$ & $9(47.3)$ \\
\hline$\geq 5 \mathrm{~cm}$ & $6(31.5)$ \\
\hline Unknown & $4(21.1)$ \\
\hline \multicolumn{2}{|l|}{ Tumor location } \\
\hline Right colon & $3(15.7)$ \\
\hline Left colon & $9(47.3)$ \\
\hline Rectum & $7(36.8)$ \\
\hline \multicolumn{2}{|l|}{ Histology } \\
\hline Adenocarcinoma & $11(57.8)$ \\
\hline Mucinous type & $6(31.5)$ \\
\hline Signet ring cell type & $2(10.5)$ \\
\hline \multicolumn{2}{|l|}{ Pathologic stage } \\
\hline Tis & $4(21.1)$ \\
\hline 1 & $3(15.7)$ \\
\hline$\|$ & $2(10.5)$ \\
\hline III & $4(21.0)$ \\
\hline IV & $6(31.5)$ \\
\hline \multicolumn{2}{|l|}{ Lymph node status } \\
\hline Negative & $9(47.3)$ \\
\hline Positive & $10(52.7)$ \\
\hline \multicolumn{2}{|l|}{ Operation type } \\
\hline Palliative & $5(26.3)$ \\
\hline Curative & $14(73.7)$ \\
\hline
\end{tabular}

Values are presented as mean (range) or number (\%).

Tis, tumor in situ.

cending colon $[7,8]$, whereas others noted the descending colon or rectum as the most common location, which is the same for adult patients [9]. In the present study, the descending colon or rectum was the most frequent location (16/19, 84.2\%). Regarding histological subtype, adenocarcinoma is the most common type, being found in $85 \%$ of adult CRC patients, followed by mucinous adenocarcinoma (10\%-15\%) and signet ring cell type (1\%) [10]. Unlike CRC in adults patients, however, in young patients, the most common types were mucinous adenocarcinoma $(6 / 19,31.5 \%)$ and signet ring cell type $(2 / 19,10.5 \%)$. Normally, mucinous adenocarcinoma and signet ring cell type result in poorer outcomes compared with adenocarcinoma. Poor outcomes were also found in 
Table 2. Details of individual patients

\begin{tabular}{|c|c|c|c|c|c|c|c|c|c|c|c|c|c|c|}
\hline Case & $\begin{array}{l}\text { Operation } \\
\text { type }\end{array}$ & Sex & $\begin{array}{l}\text { Age } \\
\text { (yr) }\end{array}$ & $\begin{array}{c}\text { BMI } \\
\left(\mathrm{kg} / \mathrm{m}^{2}\right)\end{array}$ & $\begin{array}{c}\text { CEA } \\
(\mathrm{ng} / \mathrm{dL})\end{array}$ & Tumor location & $\begin{array}{l}\text { Size } \\
(\mathrm{cm})\end{array}$ & Histology & Stage & Ps & $\begin{array}{l}\text { Life duration } \\
\text { (mo) }\end{array}$ & Survival & Recurrence & $\begin{array}{l}\text { Recurrence } \\
\text { site }\end{array}$ \\
\hline 1 & \multirow{14}{*}{$\begin{array}{l}\text { Curative } \\
\text { operation }\end{array}$} & Male & 18 & 19.60 & 1.2 & Mid rectum & 8.5 & $A C$ & Ila & & 187 & 0 & & \\
\hline 2 & & Male & 16 & 19.92 & 2.3 & Sigmoid colon & 7.0 & $A C$ & I & & 156 & 0 & & \\
\hline 3 & & Female & 13 & 13.45 & 2.0 & Ascending colon & 5.0 & SRC & IIIc & & 22 & $x$ & 0 & Ovary \\
\hline 4 & & Male & 18 & 17.34 & 2.8 & Lower rectum & 8.0 & MAC & IIIC & & 38 & $x$ & 0 & Testicle \\
\hline 5 & & Male & 16 & 18.06 & 3.6 & Lower rectum & 4.0 & $A C$ & I & & 140 & 0 & & \\
\hline 6 & & Male & 19 & 24.99 & 3.4 & Descending colon & 5.0 & MAC & $\| l l b$ & & 120 & 0 & & \\
\hline 7 & & Male & 15 & 15.41 & 1.2 & Descending colon & 0.8 & $A C$ & Tis & & 118 & 0 & & \\
\hline 8 & & Male & 15 & 21.50 & 1.0 & Sigmoid colon & 6.5 & SRC & $\mathrm{IVb}$ & 0 & 26 & $x$ & 0 & Ps \\
\hline 9 & & Male & 16 & 22.08 & 1.0 & Sigmoid colon & 2.2 & $A C$ & Tis & & 114 & 0 & & \\
\hline 10 & & Male & 19 & 26.88 & 1.3 & Sigmoid colon & 1.5 & $A C$ & Tis & & 100 & 0 & & \\
\hline 11 & & Male & 18 & 21.21 & 1.5 & Lower rectum & 2.2 & $A C$ & । & & 40 & 0 & & \\
\hline 12 & & Male & 17 & 18.96 & 16.8 & Mid rectum & 2.0 & $A C$ & Tis & & 183 & 0 & & \\
\hline 13 & & Male & 17 & 26.32 & 0.9 & Transverse colon & 6.0 & MAC & IIlb & & 21 & 0 & 0 & Anastomosis \\
\hline 14 & & Male & 19 & 25.43 & 3.9 & Sigmoid colon & 6.0 & $A C$ & Ila & & 7 & 0 & & \\
\hline 15 & \multirow{5}{*}{$\begin{array}{l}\text { Palliative } \\
\text { operation }\end{array}$} & Male & 18 & 19.15 & 2.7 & Sigmoid colon & $x$ & MAC & $\mathrm{IVb}$ & 0 & 8 & $x$ & & \\
\hline 16 & & Female & 18 & 18.92 & 116.0 & Descending colon & $x$ & MAC & $\mathrm{IVb}$ & 0 & 5 & $x$ & & \\
\hline 17 & & Female & 18 & 16.13 & 2.4 & Upper rectum & $x$ & $A C$ & $\mathrm{IVb}$ & 0 & 9 & $x$ & & \\
\hline 18 & & Male & 19 & 22.59 & 5.3 & Ascending colon & $x$ & $A C$ & $\mathrm{IVb}$ & 0 & 9 & $x$ & & \\
\hline 19 & & Mamel & 19 & 17.23 & - & Upper rectum & 4.0 & MAC & $\mathrm{IVb}$ & 0 & 6 & $x$ & & \\
\hline
\end{tabular}

$\mathrm{BMI}$, body mass index; CEA, carcinoembryonic antigen; Ps, peritoneal seeding; AC, adenocarcinoma; SRC, signet ring cell carcinoma; MAC, mucinous adenocarcinoma; Tis, tumor in situ.

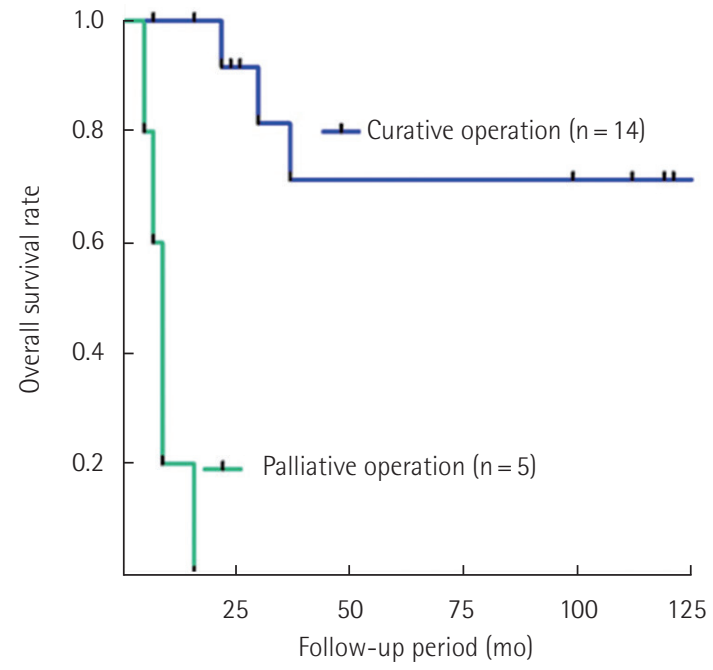

Fig. 1. Overall survival rate of curative operation group $(n=14)$ compared to palliative operation group $(n=5)$.

this study as 4 of 6 patients (66\%) with mucinous adenocarcinoma and 2 patients with signet ring cell type died during the follow-up, and the median survival was only 24 months. Six of 19 patients developed peritoneal metastasis at the time of surgery, and 4 of them (66.6\%) had mucinous adenocarcinoma and signet ring cell type.
In contrast, the patients with adenocarcinoma had a mortality rate of $18.1 \%$ during the follow-up.

Another clinical feature of teenagers with sporadic CRC was their high pathological stage on diagnosis, with $52 \%$ of all patients having stage III or higher. Furthermore, their survival rate was low, resulting in only 2 patients surviving during the follow-up. Meanwhile, all of the 9 patients (47.2\%) with stage II or lower survived during the follow-up. Therefore, this finding underscores the importance of early examination. However, teenagers usually do not undergo the clinical examination that adult patients undergo for early detection as $\mathrm{CRC}$ is so rare in teenagers, thereby resulting in the progression of CRC when a symptom-based diagnosis is made. As a result, CRC in teenagers is characterized by a low resection rate, poor prognosis, and high treatment failure compared with CRC in adults. These factors are coupled by the higher proportion of mucinous adenocarcinoma and signet ring cell type than that of adenocarcinoma, which produces a poor prognosis.

This study has limitations including the retrospective data analysis using a database and a small sample size $(n=19)$ despite the coverage period of 25 years. Given an extremely low incidence of CRC in teenagers, a multicenter study is imperative to collect more data and to provide further evidence.

Sporadic CRC is quite rare in teenagers. However, the incidence 
of histological subtypes associated with a poor prognosis tends to be higher than that in adults. In addition, their tumor stages were higher at the time of diagnosis, leading to an overall poor prognosis. Therefore, early detection at the pre-metastatic stage and subsequent radical surgical approaches, when possible, are important to improve prognosis.

\section{CONFLICT OF INTEREST}

No potential conflict of interest relevant to this article was reported.

\section{REFERENCES}

1. Jung KW, Won YJ, Kong HJ, Oh CM, Cho H, Lee DH, et al. Cancer statistics in Korea: incidence, mortality, survival, and prevalence in 2012. Cancer Res Treat 2015;47:127-41.

2. Botteri E, Iodice S, Bagnardi V, Raimondi S, Lowenfels AB, Maisonneuve P. Smoking and colorectal cancer: a meta-analysis. JAMA 2008;300:2765-78.

3. Moghaddam AA, Woodward M, Huxley R. Obesity and risk of colorectal cancer: a meta-analysis of 31 studies with 70,000 events. Cancer Epidemiol Biomarkers Prev 2007;16:2533-47.

4. Siegel R, Desantis C, Jemal A. Colorectal cancer statistics, 2014. CA
Cancer J Clin 2014;64:104-17.

5. Troisi RJ, Freedman AN, Devesa SS. Incidence of colorectal carcinoma in the U.S.: an update of trends by gender, race, age, subsite, and stage, 1975-1994. Cancer 1999;85:1670-6.

6. Durno C, Aronson M, Bapat B, Cohen Z, Gallinger S. Family history and molecular features of children, adolescents, and young adults with colorectal carcinoma. Gut 2005;54:1146-50.

7. Yang R, Cheung MC, Zhuge Y, Armstrong C, Koniaris LG, Sola JE. Primary solid tumors of the colon and rectum in the pediatric patient: a review of 270 cases. J Surg Res 2010;161:209-16.

8. Du F, Shi SS, Sun YK, Wang JW, Chi Y. Clinicopathological characteristics and prognosis of colorectal cancer in chinese adolescent patients. Chin Med J (Engl) 2015;128:3149-52.

9. Sultan I, Rodriguez-Galindo C, El-Taani H, Pastore G, Casanova $M$, Gallino G, et al. Distinct features of colorectal cancer in children and adolescents: a population-based study of 159 cases. Cancer 2010;116:758-65.

10. Lin J, Qiu M, Xu R, Dobs AS. Comparison of survival and clinicopathologic features in colorectal cancer among African American, Caucasian, and Chinese patients treated in the United States: Results from the surveillance epidemiology and end results (SEER) database. Oncotarget 2015;6:33935-43. 